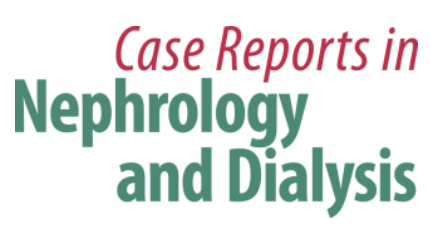

\title{
Successful Treatment of Idiopathic Eosinophilic Peritonitis by Oral Corticosteroid Therapy in a Continuous Ambulatory Peritoneal Dialysis Patient
}

\author{
Yaowen Xu Chenni Gao Jing Xu Nan Chen \\ Department of Nephrology, Ruijin Hospital, Shanghai Jiao Tong University School of \\ Medicine, Shanghai, China
}

\section{Key Words}

Idiopathic eosinophilic peritonitis - Continuous ambulatory peritoneal dialysis · Turbidness . Corticosteroid therapy

\begin{abstract}
Eosinophilic peritonitis is a well-described complication of peritoneal dialysis and is often associated with either a reaction to the dialysis system constituent (tubing, sterilant or solution) or an underlying bacterial or fungal reaction. We report a case of eosinophilic peritonitis, which is treated by oral prednisone acetate therapy. A 43-year-old female patient developed end-stage renal disease and underwent continuous ambulatory peritoneal dialysis for 2.5 years. The patient received $2,000 \mathrm{ml}$ of $1.5 \%$ dialysis solution (PD2) with three exchanges daily and $2,000 \mathrm{ml}$ of $2.5 \%$ PDF overnight (PD2). She went to the consultation because of a constant turbid peritoneal dialysis effluent for 3 months without abdominal pain. Repeated peritoneal effluent samples showed an elevated white blood cell count of 500 cells $/ \mathrm{mm}^{3}$, with $87 \%$ eosinophils. The peripheral blood test revealed a white blood cell count of $3.8 \times$ $10^{9} /$, with $32.2 \%$ eosinophils. Etiology like bacterial and fungal infection was excluded by peritoneal fluid culture. Turbidness persisted in spite of diagnostic antibiotic treatment. Given the fact that we found a significant elevation of eosinophils in the peripheral blood and an absolute increase in the eosinophil count of $>30 / \mathrm{mm}^{3}$ in dialysis fluid (up to $400 / \mathrm{mm}^{3}$ in our patient), obvious dialysate effluent turbidness, negative results of repeated peritoneal fluid cultures, inefficacy of antibiotic therapy, and negativity of serum tumor and immunological markers, we drew the conclusion that the patient had idiopathic eosinophilic peritonitis. Oral
\end{abstract}




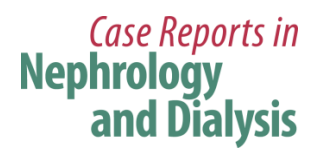

\begin{tabular}{l|l}
\hline \multicolumn{2}{l}{ Case Rep Nephrol Dial 2015;5:130-134 } \\
\hline DOI: 10.1159/000431085 & $\begin{array}{l}\text { ○ 2015 S. Karger AG, Basel } \\
\text { www.karger.com/cnd }\end{array}$ \\
\hline
\end{tabular}

Xu et al.: Successful Treatment of Idiopathic Eosinophilic Peritonitis by Oral Corticosteroid Therapy in a Continuous Ambulatory Peritoneal Dialysis Patient

corticosteroid was administered at once (20 mg prednisone acetate daily), which was gradually weaned off and stopped over an 8-week period. Afterwards, the dialysis effluent became clear, and the cytological analysis showed that the white blood cell count decreased to $1 \times$ $10^{6} / \mathrm{l}$, with no eosinophils. This case reminds us that the diagnosis of eosinophilic peritonitis should be considered when repeated cultures are always negative and the turbidness of peritoneal dialysis effluent persists in spite of an antibiotic therapy.

(C) 2015 S. Karger AG, Basel

\section{Case Report}

A 43-year-old female patient developed end-stage renal disease due to chronic glomerulonephritis and underwent continuous ambulatory peritoneal dialysis (CAPD) for 2.5 years (started in January 2012). Her peritoneal dialysis regime included 2,000 $\mathrm{ml}$ of $1.5 \%$ peritoneal dialysis solution (Dianeal 1.5\%, Baxter, International Inc.) with three exchanges daily (PD2) and 2,000 ml of 2.5\% PDF overnight (PD2). Her daily peritoneal dialysis ultrafiltration volume was $500-800 \mathrm{ml}$ and her urine output was $800-1,000 \mathrm{ml} / 24 \mathrm{~h}$. The patient denied having had any systemic diseases or a history of allergic or infectious diseases. In general, her CAPD therapy went well during the past 30 months, and the peritoneal dialysis effluent was always clear.

From May 2014, the patient observed cloudy peritoneal effluent without abdominal pain or fever. The ultrafiltration volume was stable. An effluent cytological study and bacterial/fungal culture were demanded before the antibiotic application. The former showed a white blood cell (WBC) count of $630 \times 10^{6} / \mathrm{l}$, with $80 \%$ polynuclear cells, while the latter was negative. Despite all treatments, such as peritoneal lavage, diagnostic antibiotic treatment by intraperitoneal injection of aminoglycosides (amikacin) combined with first-generation cephalosporins (cefazolin) for 14 days, the effluent was still turbid. The second peritoneal fluid culture was performed 10 days after the antibiotic application, which was, however, still negative; thus, a bacterial/fungal culture was demanded. Therefore, we changed the antibiotic regime of intraperitoneal injection of ceftazidime and vancomycin to 21 days. Intraperitoneal urokinase 5,000 IU/l was also added to each dialysate. There was still no improvement of the turbidness, but the ultrafiltration was always stable. The patient was hospitalized in July 2014.

\section{Physical Examination on Admission}

Our 43-year-old patient weighed $65 \mathrm{~kg}$ and measured $165 \mathrm{~cm}$ (BMI 23.8). Her blood pressure was $140 / 80 \mathrm{~mm} \mathrm{Hg}$, with a heart rate of $80 \mathrm{bpm}$. There was no rash or purpura. Pulmonary auscultation was normal. Abdominal palpation revealed no tenderness, tension or rebound pain, and no lower extremity edema was found.

In July 2014, the complete blood count (CBC) revealed a WBC count of $3.8 \times 10^{9} / \mathrm{l}$, with $32.2 \%$ eosinophils, and there were up to $500 \times 10^{6} / 1$ leukocytes in the peritoneal effluent, with $87 \%$ eosinophils. The absolute eosinophil count was $435 / \mathrm{mm}^{3}$ (before the antibiotic application). The peritoneal effluent culture showed no growth of aerobic or anaerobic bacteria, or fungi, and negativity for acid-fast stain. The patient remained asymptomatic, and the antibiotics were then stopped.

Given the fact that there was a significant elevation of eosinophils in the peritoneal effluent with a ratio of $87 \%$ and an absolute eosinophil count of $>30 / \mathrm{mm}^{3}$ (up to $435 / \mathrm{mm}^{3}$ ), the patient was diagnosed with eosinophilic peritonitis (EP). The etiological examinations included repeated effluent bacteria, fungi, and Mycobacterium tuberculosis detection and cultivation; serum tumor markers, serum immunological markers like ANA, ENA and ANCA, 


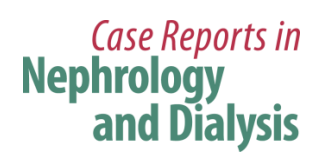

\begin{tabular}{l|l}
\hline Case Rep Nephrol Dial 2015;5:130-134 \\
\hline DOI: 10.1159/000431085 & $\begin{array}{l}\text { ○ 2015 S. Karger AG, Basel } \\
\text { www.karger.com/cnd }\end{array}$ \\
\hline
\end{tabular}

Xu et al.: Successful Treatment of Idiopathic Eosinophilic Peritonitis by Oral Corticosteroid Therapy in a Continuous Ambulatory Peritoneal Dialysis Patient

and blood allergen tests were all negative. Chest and abdominal injected computed tomography did not reveal any sign of malignancy. However, there was a slight elevation in erythrocyte sedimentation rate (ESR) and C-reactive protein (CRP) (table 1).

Ketotifen (1 mg daily p.o.) was given as anti-allergic treatment along with low-dose oral corticosteroid therapy. The patient commenced oral prednisone acetate with a daily dose of $20 \mathrm{mg}$. Over the next $24 \mathrm{~h}$, her peritoneal dialysis effluent became clear. Prednisone acetate was rapidly reduced and stopped over a 2-week period, but 3 days after that, the peritoneal dialysis effluent turned turbid again. Thus, we restarted a low dose of prednisone acetate $(20$ mg daily p.o.), which was gradually weaned off and stopped over an 8-week period. During the therapy course, the patient had no complaint of abdominal pain, and the dialysis fluid remained clear. In September 2014, we reanalyzed the dialysis effluent cytology demonstrating that the polynuclear cell count decreased to $1 \times 10^{6} / \mathrm{l}$, with no eosinophils (fig. 1). The CBC showed a WBC count of $9.2 \times 10^{9} / \mathrm{l}$, with $1.1 \%$ eosinophils.

\section{Laboratory Examination}

In May 2014, the following examinations were performed: CBC: WBC $7.3 \times 10^{9} / \mathrm{l}$ with 12.8\% eosinophils, Hgb 112/l, PLT $217 \times 10^{9} / \mathrm{l}$; SGPT 14 IU/l, SGOT 17 IU/l, Alb 28 g/l, Scr $897 \mu \mathrm{mol} / \mathrm{l}$; ESR $38 \mathrm{~mm} / \mathrm{h}$, CRP $1.12 \mathrm{mg} / \mathrm{lRF} 29 \mathrm{IU} / \mathrm{ml}$, IgG 1,800 mg/dl, IgA $392 \mathrm{mg} / \mathrm{dl}$; dialysis effluent cytology: WBC $630 \times 10^{6} / \mathrm{l}$ with $80 \%$ polynuclear cells; dialysis effluent culture: negative.

In July 2014, the following examinations were performed: CBC: WBC $3.8 \times 10^{9} / \mathrm{l}$ with $32.2 \%$ eosinophils, Hgb 100/l, PLT $202 \times 10^{9} / \mathrm{l}$; SGPT 15 IU/l, SGOT 16 IU/l, Alb 20 g/l, Scr $856 \mu \mathrm{mol} / \mathrm{l}$; ESR $42 \mathrm{~mm} / \mathrm{h}$, CRP $0.45 \mathrm{mg} / \mathrm{lRF} 29 \mathrm{IU} / \mathrm{ml}$, IgG $574 \mathrm{mg} / \mathrm{dl}$, IgA $81 \mathrm{mg} / \mathrm{dl}$; dialysis effluent cytology: WBC $500 \times 10^{6} / \mathrm{l}$ with $87 \%$ eosinophils; dialysis effluent culture: negative.

In August 2014 ( 4 weeks), the following examinations were performed: CBC: WBC $8.99 \times 10^{9} / \mathrm{l}$ with $1.3 \%$ eosinophils, Hgb 91/l, PLT $242 \times 10^{9} / \mathrm{l}$; SGPT $22 \mathrm{IU} / \mathrm{l}$, SGOT $18 \mathrm{IU} / \mathrm{l}$, Alb 17g/l, Scr $816 \mu \mathrm{mol} / \mathrm{l}$; dialysis effluent cytology: WBC $60 \times 10^{6} / \mathrm{l}$ with $20 \%$ eosinophils; dialysis effluent culture: negative.

In September 2014 ( 8 weeks), the following examinations were performed: CBC: WBC $9.2 \times 10^{9} / \mathrm{l}$ with $0.9 \%$ eosinophils, Hgb 120/l, PLT $279 \times 10^{9} / \mathrm{l}$; SGPT $18 \mathrm{IU} / \mathrm{l}$, SGOT $17 \mathrm{IU} / \mathrm{l}$, Alb $25 \mathrm{~g} / \mathrm{l}$, Scr $769 \mu \mathrm{mol} / \mathrm{l}$; dialysis effluent cytology: WBC $1.0 \times 10^{6} / \mathrm{l}$ with no eosinophil; dialysis effluent culture: negative.

\section{Discussion}

Idiopathic EP is a well-known generally benign complication of peritoneal dialysis [1]. EP in CAPD patients was first described in 1967 by Lee and Schoen [2]. It is defined as an absolute eosinophil count of $>30 / \mathrm{mm}^{3}$ in the dialysis fluid of patients receiving maintenance peritoneal dialysis [3]. It usually occurs within the first 3 months after initiating dialysis [4], although it has been reported to occur much later (Fontán et al. [5] reported 5 cases who developed idiopathic EP after $>6$ months and as late as after 63 months). The cause of EP is obscure and the majority of reports link its occurrence to two major causal etiologies: (a) idiopathic EP, which tends to occur within the first 3 months of CAPD initiation and is attributed to hypersensitivity to peritoneal dialysis materials (catheter or solutions), drugs, icodextrin, air introduced into the peritoneal cavity at the time of catheter placement, or the mechanical irritant action of large volumes of fluid on the peritoneum, and (b) infectionrelated EP, which is most commonly due to fungal and parasitic or viral infection, and then following treatment of bacterial peritonitis [6]. The incidence of idiopathic EP was reported- 


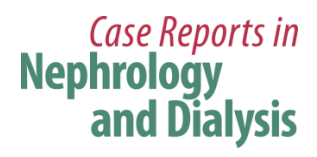

\begin{tabular}{l|l}
\hline Case Rep Nephrol Dial 2015;5:130-134 \\
\hline DOI: 10.1159/000431085 & $\begin{array}{l}\text { ○ 2015 S. Karger AG, Basel } \\
\text { www.karger.com/cnd }\end{array}$ \\
\hline
\end{tabular}

Xu et al.: Successful Treatment of Idiopathic Eosinophilic Peritonitis by Oral Corticosteroid Therapy in a Continuous Ambulatory Peritoneal Dialysis Patient

ly very high in the 1980s [2], but decreased dramatically afterwards. This may have been due to an absent progress and a consequent loss of interest in this entity, but also owing to the improvements in the quality of peritoneal dialysis materials. In all cases, peritoneal fluid eosinophilia can be easily diagnosed during the first weeks of peritoneal dialysis therapy, after prospective cytological evaluation of seemingly normal peritoneal fluids or, more frequently, in the presence of mild, transient, and asymptomatic fluid turbidity, which is often demonstrated only after the nocturnal dwell. Overt EP is much less common, although not rare. Mild peritoneal fluid eosinophilia is self-limited and has a uniformly benign prognosis, while overt idiopathic EP may follow a persistent or recurrent clinical course, which is often symptomatic, and can benefit from short courses of therapy with steroids [7], diphenhydramine [7] or ketotifen [8].

Here we described the case of a 43-year-old female patient with end-stage renal disease having undergone CAPD for 2.5 years, who had had cloudy dialysis effluent for 3 months without abdominal pain. She was diagnosed with EP, which was relieved by oral prednisone acetate therapy. First-line therapy was an intraperitoneal injection of a combined antibiotic (antibiotic with a Gram-positive and Gram-negative spectrum) according to its clinical manifestation, which, unfortunately, seemed ineffective.

Our clinical investigations can be summed up as follows: (1) a raised blood eosinophil count of $1.2 \times 10^{9} / \mathrm{l}$; (2) dialysis fluid cytology revealing a WBC count between 500 and 600 cells $/ \mathrm{mm}^{3}$, with $87 \%$ eosinophils; (3) an absolute eosinophil count of $>30 / \mathrm{mm}^{3}$ in dialysis fluid (up to $400 / \mathrm{mm}^{3}$ ), and (4) elevated CRP (0.45-1.12 mg/dl) and ESR (38-42 mm/h). We suggested that the turbidness of the dialysis effluent was caused by EP. This diagnosis was further confirmed to be 'idiopathic' by the negative results of the dialysis effluent culture, and serum tumor and immunological markers.

Compared to the literature, the patient had undergone CAPD for a more extended period (2.5 years). However, the longest interval period reported is 63 months [5]. In our patient, an allergic etiology seemed most probable after all etiological examinations. We diagnosed idiopathic EP, and oral administration of prednisone acetate was started at once. After a quick, unsuccessful withdrawal, we recommenced its administration at a small dose (20 $\mathrm{mg}$ daily), which was gradually weaned off and stopped after an 8-week period. During the therapy course, the patient had no complaint of abdominal pain, and her peritoneal dialysis fluid was clear.

With the exception of fungal EP [6], EP is usually a benign sterile process. A spontaneous remission is expected after a period of up to several months of continued dialysis. Unlike in other cases of persistent infectious peritonitis, it is critical that dialysis catheter removal is not indicated. A short course of low-dose oral prednisone acetate has been suggested for patients to maintain catheter patency if the peritoneal fluid is markedly turbid. Because of potential side effects of long-term prednisone acetate therapy, it would not be appropriate for the majority of asymptomatic self-limited cases [9]. This case reminds us that the diagnosis of EP should be considered when repeated cultures are always negative and the turbidness of peritoneal dialysis effluent persists in spite of an antibiotic therapy.

\section{Disclosure Statement}

The authors declare that no financial or other conflict of interest exists in relation to the content of the article. 
Case Reports in

Nephrology and Dialysis

\begin{tabular}{l|l}
\hline \multicolumn{2}{l}{ Case Rep Nephrol Dial 2015;5:130-134 } \\
\hline DOI: 10.1159/000431085 & $\begin{array}{l}\text { ○ 2015 S. Karger AG, Basel } \\
\text { www.karger.com/cnd }\end{array}$ \\
\hline
\end{tabular}

Xu et al.: Successful Treatment of Idiopathic Eosinophilic Peritonitis by Oral Corticosteroid Therapy in a Continuous Ambulatory Peritoneal Dialysis Patient

\section{References}

1 Ejaz AA, Fitzpatrick PM, Durkin AJ, et al: Pathophysiology of peritoneal fluid eosinophilia in peritoneal dialysis patients. Nephron 1999;81:125-130.

2 Lee S, Schoen I: Eosinophilia of peritoneal fluid and peripheral blood associated with chronic peritoneal dialysis. Am J Clin Pathol 1967;47:638-640.

3 Piraino BM, Silver MR, Dominguez JH, et al: Peritoneal eosinophils during intermittent peritoneal dialysis. Am J Nephrol 1984;4:152-157.

4 Chan MK, Chow L, Lam SS, et al: Peritoneal eosinophilia in patients on continuous ambulatory peritoneal dialysis: a prospective study. Am J Kidney Dis 1988;11:180-183.

5 Fontán MP, Rodríguez-Carmona A, Galed I, et al: Incidence and significance of peritoneal eosinophilia during peritoneal dialysis-related peritonitis. Perit Dial Int 2003;23:460-464.

6 Rosner MH, Chhatkuli B: Vancomycin-related eosinophilic peritonitis. Perit Dial Int 2010;30:650-652.

7 Thakur SS, Unikowsky B, Prichard S: Eosinophilic peritonitis in CAPD: treatment with prednisone and diphenhydramine. Perit Dial Int 1997;17:402-403.

8 Tang S, Lo CY, Lo WK, et al: Resolution of eosinophilic peritonitis with ketotifen. Am J Kidney Dis 1997;30:433-436.

9 Asghar R, Woodrow G, Turney JH: A case of eosinophilic peritonitis treated with oral corticosteroids. Perit Dial Int 2000;20:579-580.

Table 1. Laboratory analysis before and after the treatment

\begin{tabular}{lcccc}
\hline & May 2014 & Jul 2014 & Aug 2014 & Sep 2014 \\
\hline WBC, $\times 10^{9} / \mathrm{l}$ & 7.3 & 3.8 & 8.99 & 9.2 \\
Eosinophil, \% & 12.8 & 32.2 & 1.3 & 1.1 \\
Hemoglobin, g/l & 112 & 100 & 91 & 120 \\
ALT, IU/l & 217 & 202 & 242 & 279 \\
AST, IU/l & 14 & 15 & 22 & 18 \\
Platelet, $\times 10^{9} / \mathrm{l}$ & 17 & 16 & 18 & 17 \\
Albumin, g/l & 28 & 20 & 17 & 25 \\
Creatinine, mmol/l & 897 & 856 & 816 & 769 \\
ESR, mm/h & 38 & 42 & - & - \\
CRP, mg/l & 1.12 & 0.45 & - & - \\
Dialysis fluid culture & negative & negative & negative & negative \\
\hline
\end{tabular}

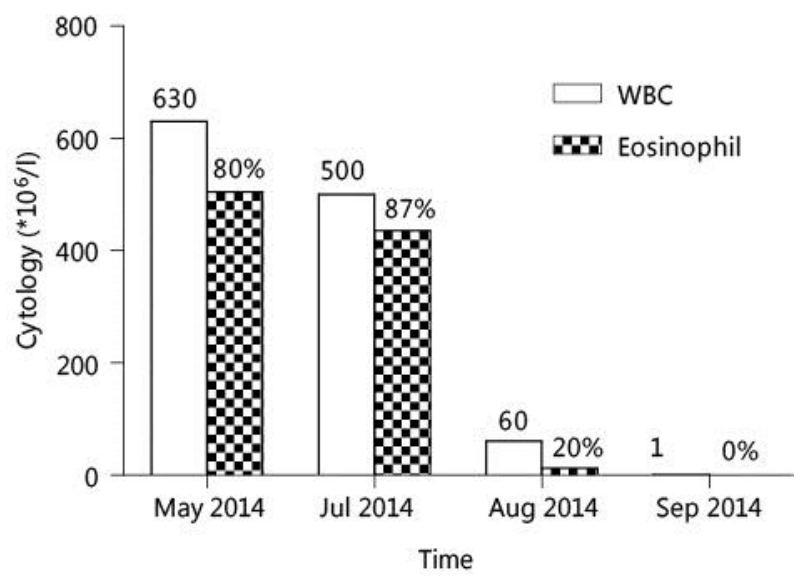

Fig. 1. Cytological analysis of the dialysis effluent before and after treatment. 